REVESCO. Revista de Estudios Cooperativos ISSN: $1885-8031$

http://dx.doi.org/10.5209/REVE.62490

\title{
Banca cooperativa y transformación digital: hacia un nuevo modelo de relación con sus socios y clientes
}

\author{
Ricardo Palomo Zurdo ${ }^{1}$, Yakira Fernández Torres ${ }^{2}$ y Milagros Gutiérrez Fernández ${ }^{3}$
}

Recibido: 2 de julio de 2018 / Aceptado: 3 de diciembre de 2018

Resumen. Este trabajo analiza cómo la configuración de una nueva sociedad digital está cambiando los modelos de relación entre las empresas y sus usuarios o consumidores, centrándose en el modelo de relación entre las cooperativas de crédito y sus socios y clientes. El desarrollo de la economía digital incide tanto en los procesos tecnológicos como en la forma de relación con los usuarios de los servicios financieros. Así, la experiencia de cliente y la satisfacción con los procesos de las entidades ocupan actualmente el centro de atención de las estrategias de las entidades financieras. Para analizar esta transformación digital de la sociedad y sus efectos sobre la banca cooperativa española se ha realizado un estudio cuantitativo y cualitativo mediante el procesamiento de un cuestionario remitido a las cooperativas de crédito españolas, con la colaboración de la UNACC y del Grupo Cajamar. Los resultados obtenidos, que se presentan empleando un análisis gráfico y estadístico, arrojan interesantes valoraciones y constataciones de la actuación del sector en relación con la transformación digital de la economía y de la sociedad, y obligan a analizar si el modelo de red territorial tradicional y cercanía al usuario pierde competitividad tanto por razón de las nuevas tecnologías como por el progresivo cambio en el perfil y capacidades tecnológicas de los usuarios de los productos y servicios financieros.

Palabras clave: Cooperativas de crédito; Experiencia de cliente; Exclusión financiera; Digitalización; Fintech; Bigtech.

Claves Econlit: G21, O35, O39.

\section{[en] Cooperative banking and digital transformation: towards a new relationship model with members and clients}

\begin{abstract}
This paper analyzes how the new digital society in changing the relationship model between companies and their users or consumers, focusing on the how co-operative banks manage their relations with members and customers. The development of the digital economy affects both the technological processes and the way in which is built the relationship with the users of financial services. Thus, the strategy of the financial institutions is currently focused on the customer experience and their satisfaction with the service processes. To analyze this digital transformation of society and its effects on Spanish cooperative banks, a quantitative and qualitative study has been carried out through the processing of a questionnaire sent to Spanish credit cooperatives, with the
\end{abstract}

1 Universidad CEU San Pablo, España

Dirección de correo electrónico: palzur@,ceu.es

2 Universidad de Extremadura, España

Dirección de correo electrónico: yakiraft@unex.es

3 Universidad de Extremadura, España

Dirección de correo electrónico: mgutierrezf@unex.es 
collaboration of UNACC and the Cajamar Group. The results show, using a graphical and statistical analysis, interesting issues about the transformation of the relationship between the sector in relation to the digital transformation of the economy and society, and make it necessary to analyze if the traditional competitiveness based on the territorial model and closeness to the user loses the it competitive advantage with the new technologies and due to the progressive change in the profile and technological capabilities of users and financial services.

Keywords: Credit unions; Customer experience; Financial exclusion; Digitization; Fintech; Bigtech.

Sumario. 1. Introducción. 2. Implicaciones de la transformación digital en el sector financiero y en la banca cooperativa. 3. Confección de la muestra y metodología. 4. Resultados del análisis. 5. Conclusiones. 6. Referencias bibliográficas.

Cómo citar: Palomo Zurdo, R., Fernández Torres, Y. y Gutiérrez Fernández, M. (2018) Banca cooperativa y transformación digital: hacia un nuevo modelo de relación con sus socios y clientes. REVESCO. Revista de Estudios Cooperativos, Tercer Cuatrimestre, $\mathrm{N}^{\mathrm{o}}$ 129, pp. 161-182. DOI: 10.5209/REVE.62490.

\section{Introducción}

El impacto de la aguda y larga crisis económico-financiera acontecida entre 2008 y 2014, la desaparición y la transformación de las antiguas cajas de ahorros, la concentración de muchas entidades bancarias, la fuerte reducción del número de oficinas y empleados, además de la intensa y exigente regulación del sector financiero, han transformado como nunca el sistema bancario (King, 2014).

La irrupción de la intensa regulación (Basilea III) ha supuesto una mayor exigencia en volumen y en calidad del capital de las entidades financieras, pero también mayores requisitos de liquidez (Mínguez, 2011). Al mismo tiempo, se ha intensificado la supervisión y se ha creado un mecanismo de resolución para intervenir las entidades financieras con problemas y, paralelamente, se ha obligado a fortalecer el gobierno corporativo de las entidades, presionando así la rentabilidad del sector.

Si esto ya era juzgado como la "tormenta perfecta", en paralelo y con una cronología similar a los hechos anteriores, se estaba gestando y produciendo la incorporación de nuevas y disruptivas tecnologías en el sector financiero y en el conjunto de las actividades económicas que, ahora, parecen marcar el comienzo de una transición desde el modelo de banca ya tradicional o clásico hacia un nuevo modelo de banca que debe desarrollarse en un nuevo contexto: el de una nueva sociedad y economía digital que se encuentra en acelerada transformación.

En el ámbito financiero, la entrada en juego de las empresas del denominado sector Fintech, así como la ya notoria presencia de las grandes empresas tecnológicas con actividades financieras -lo que se ha conceptualizado como Techfin-, está replanteando muchas de las funciones de la intermediación bancaria tradicional en sus líneas de negocio.

Así, por ejemplo, incluso en el sofisticado ámbito de la gestión de patrimonios se está abriendo paso la gestión robotizada o algorítmica, lo cual plantea incertidumbres e inquietudes, pero también aporta oportunidades de diferenciación competitiva. Los principales bancos del mundo están adquiriendo compañías fintech o están creando sus propias líneas de negocio desgajadas de las clásicas; 
mientras que otras están firmando alianzas estratégicas para el desarrollo de nuevas tecnologías, como es el caso de las aplicaciones de blockchain. También, prácticamente todas las entidades relevantes han incorporado ya la utilización de big data para sistemas de predicción, de gestión de productos, de análisis de la clientela, etc. Así mismo, la inteligencia artificial promete ser, junto con la tecnología blockchain, uno de los motores de la transformación del sector bancario a nivel global.

Por ello, no sólo la entrada en el mercado financiero de las compañías fintech, o de las grandes tecnológicas suponen la caída de tradicionales barreras de entrada al sector (Akkizidis y Stagars, 2016), sino que se está gestando la futura transformación mediante tecnologías que permiten la incorporación de robots financieros de asesoramiento de inversión (roboadvisors), la explotación del big data (Chishti y Barberis, 2016), o la temida desintermediación que promete la revolucionaria descentralización de blockchain.

Por lo que respecta a la banca cooperativa, que cuenta con una importante presencia en la mayor parte de los países del mundo y, en particular, en países europeos de primera línea, como Alemania, Francia o Países Bajos, la cuestión de la transformación digital, tanto en sus procesos operativos internos, como en los que tienen que ver con la relación de servicios con su base societaria y de clientes, se está convirtiendo en el elemento clave de su estrategia de futuro.

Las cooperativas de crédito españolas también se han sumado a este proceso de asimilación tecnológica en sus diferentes áreas de actividad, como lo hicieron en épocas anteriores con la llegada de Internet o la computarización de sus procesos, pues la sociedad y los medios de interacción han cambiado; y porque los clientes exigen, cada vez más, una experiencia de servicios financieros ágiles y convenientes.

Desde otro punto de vista, la referida crisis y la transformación del sector bancario han llevado, incluso, a cierta situación de exclusión financiera, con un creciente número de poblaciones donde ya no hay oficinas bancarias. Se trata de una tendencia que se inició hace unos años, pero que se ha agudizado a partir del año 2015, y que preocupa a algunas capas de la población, en particular, a las de mayor edad.

Sin embargo, parece que los nuevos desarrollos tecnológicos pueden mitigar su efecto; y que otras amplias capas de edad no se verán afectadas por esa reducción de la red presencial, sino que, al contrario, darán prioridad a los canales virtuales.

Obviamente, esto puede afectar a la posición competitiva de la banca cooperativa, fundamentada tradicionalmente en la cercanía física a los socios y clientes y en su presencia y arraigo territorial, construyendo estables y sólidas relaciones de base profesional-personal en la gestión del día a día, y estando especialmente arraigada en muchas zonas y sectores de actividad en las que otras entidades financieras no cooperativas estaban menos presentes.

En suma, cabe plantearse si todos estos hechos y tendencias (transformación digital, nuevos modelos de relación con los socios y clientes y reducción de la importancia de la red de oficinas) pueden llevar a una pérdida de la ventaja competitiva tradicional de la banca cooperativa, sustentada, tradicionalmente, en su arraigo territorial y en la relación personal y presencial directa con los socios y clientes. 
Por ello, en este contexto de cambios, transformación e incertidumbres, pero también de oportunidades, este trabajo analiza la percepción de las cooperativas de crédito españolas sobre el impacto de la transformación digital, tanto en su visión interna, como en su modelo de relación externa con sus socios y clientes.

Este trabajo constituye, hasta donde se conoce, el primer estudio sobre esta la novedosa cuestión de la transformación digital en el contexto de la banca cooperativa, desarrollado, además, en el año 2018, por lo que incluye así la percepción del sector sobre impactos tecnológicos que eran impensables dos años atrás.

Para el desarrollo de la investigación se ha contado con la inestimable colaboración de la Unión Nacional de Cooperativas de Crédito (UNACC) y del Grupo Cajamar, lo que ha permitido obtener información cuantitativa y cualitativa mediante un cuestionario dirigido a los responsables de las entidades, cuyos resultados se examinan mediante un análisis gráfico y estadístico-descriptivo. Como hallazgo reseñable cabe citar la clara percepción de la amenaza de entrada en el ámbito de la actividad bancaria de las nuevas empresas fintech y de los grandes operadores tecnológicos; así como la diferente evolución en el grado de adaptación digital de las entidades de banca cooperativa y de sus socios y clientes.

Este trabajo se compone de un total de cinco apartados, además de este primero de introducción. El segundo apartado tratará de reflejar los efectos que la transformación digital está teniendo en el sector financiero y, más concretamente, en la banca cooperativa española. El tercer epígrafe se centrará en la presentación de la muestra y la metodología del análisis realizado. En cuarto lugar, se presentarán los resultados de estudio $\mathrm{y}$, por último, quedarán reflejadas las conclusiones obtenidas y las referencias bibliográficas empleadas.

\section{Implicaciones de la transformación digital en el sector financiero y en la banca cooperativa}

El empoderamiento que la tecnología ofrece a los ciudadanos conlleva la necesidad de un cambio de modelo relacional entre las entidades financieras y sus usuarios. La banca no puede evitar verse afectada por la digitalización y no reconocerlo, únicamente retrasa la urgencia de afrontarlo, pues debe haber una banca digital viable, rentable y amable con los clientes al final del camino (Massanell, 2016).

La convalecencia del sistema bancario tras la profunda crisis económicofinanciera ha discurrido paralela en el tiempo a la referida transformación del sector financiero-bancario, tras haber golpeado con fuerza inusitada al sistema (King, 2014) y haber provocado una cuasi-extinción darwiniana avivada por un shock regulatorio interminable que, aunque pretende vacunar al sector contra futuras crisis, también merma su crecimiento y actividad y parece favorecer el desarrollo de nuevas especies más adaptadas y ágiles, como son las empresas del sector fintech, o el descubrimiento de nuevas funciones por parte de especies muy poderosas, como las grandes compañías tecnológicas. De este modo, la intensidad del proceso de reestructuración y el impacto normativo en sus múltiples facetas se antojan metafóricamente similares a aquella lejana extinción de los saurios: 
sucumbieron las especies dominantes y, en cambio, sobrevivieron las que mejor se adaptaron.

Dicha reordenación bancaria ha afectado también al sistema de banca cooperativa española, que se caracteriza actualmente por la existencia de varios grupos fruto del proceso de concentración reciente y de la evolución del sistema previo a la crisis financiera (véase figura 1).

Figura. 1. El sistema de banca cooperativa en España.

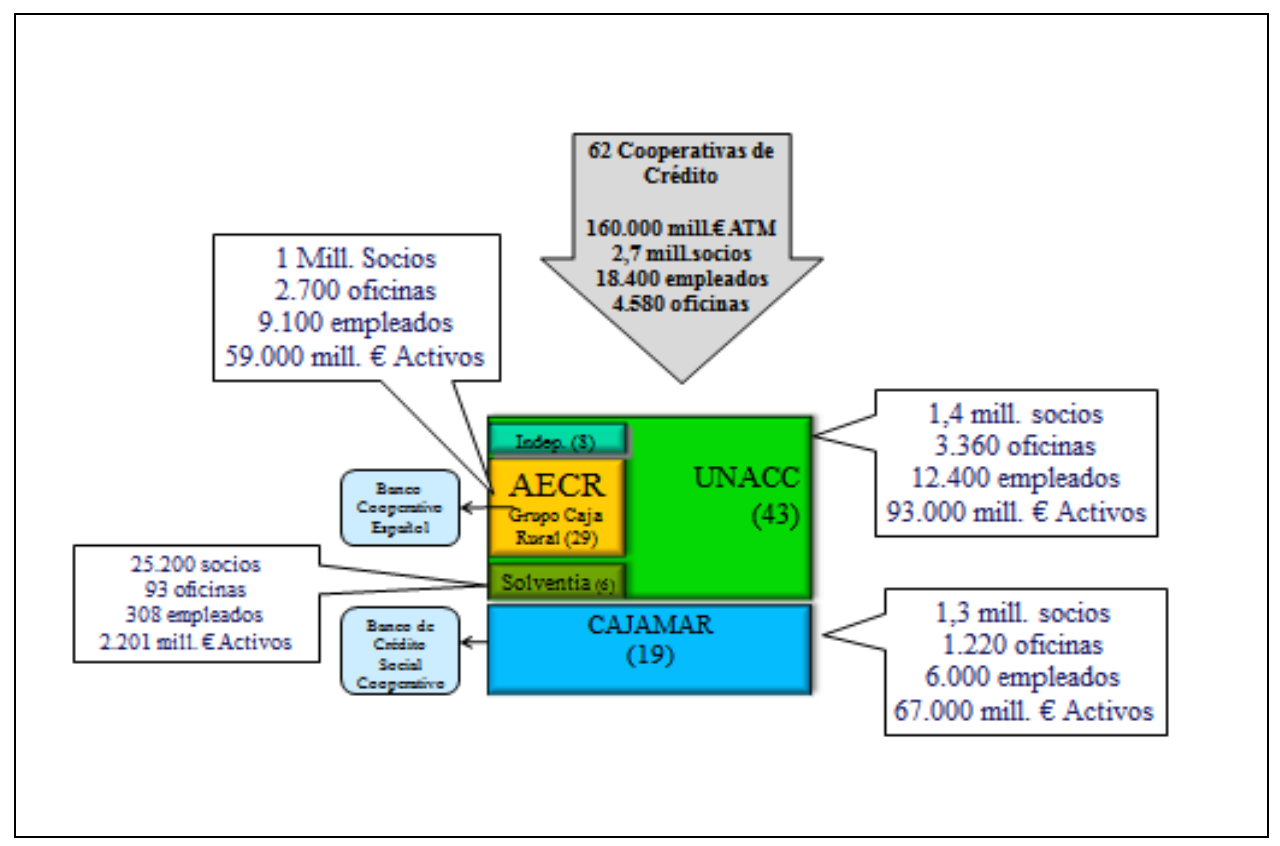

Fuente: Palomo (2017).

De este modo, la banca cooperativa en España comprende a un conjunto de 62 cooperativas de crédito que vinculan a más de 2,7 millones de socios y cerca de 11 millones de clientes. En términos económicos alcanzan un activo de 140.000 millones de euros, con una cuota del $6,75 \%$ de los depósitos y el $6,1 \%$ de los créditos, empleando a casi 20.000 personas en una amplia red de 4.600 oficinas. El sector incluye, tanto a las cajas rurales (aproximadamente el $80 \%$ del sector por dimensión de los activos), como a las cajas populares y profesionales ${ }^{4}$.

Las cooperativas de crédito son entidades que fundamentan su modelo relacional en "hablar el mismo idioma" que sus socios y clientes y que han sabido prestar algo más que servicios financieros, resultando así una suerte de

4 Datos tomados agregando el conjunto del sector en España, partiendo de las entidades vinculadas al Grupo Cajamar (19) y las asociadas a la Unión Nacional de Cooperativas de Crédito UNACC (43). Además hay dos entidades en liquidación (Caja de Crédito de Alcoy y Caja Rural de la Carlota). 
compromiso y vinculación que se realimenta, fortaleciendo el propio vínculo (EACB, 2014; Oliver Wyman, 2014).

Ahora bien, el nuevo modelo relacional del sector bancario en relación con sus usuarios, potencia la banca a distancia frente al modelo comercial tradicional de proximidad, el característico de la banca cooperativa, por lo que ésta necesita poner de manifiesto la trascendencia de su proceso de innovación (Chesbrough, 2010) y ofrecer una respuesta estratégica que le permita mantener su posición competitiva en un entorno en el que han entrado nuevos actores (Carbó y Rodríguez-Fernández, 2014, 2016, y 2017; Maudos, 2017a y 2017b).

Desde otro punto de vista, la banca debe estar atenta al proceso de cambio sociocultural de la nueva sociedad digital con la incorporación de nuevas generaciones: la ya activa de los millennials; y la más reciente de los centennials (los nacidos en el S. XXI) que tienen una diferente orientación en sus medios de relación a efectos de consumo, de ocio, de comunicación $\mathrm{y}$, también, de ahorro e inversión.

Si el modelo relacional bancario cambia por razón de la incorporación de nuevas tecnologías y también por el cambio en los usos y costumbres de los usuarios, resulta necesario adaptar las organizaciones y rediseñar el modelo tradicional de negocio (Morris, 2006; Giesen, Riddleberger, Christensen y Bell, 2010) imponiendo una cultura de innovación abierta que se oriente hacia el diseño de una nueva cadena de valor y un nuevo modelo de banca relacional digital.

En este sentido, un reto importante es que las entidades estén alineadas con sus clientes, de modo que éstos acojan favorablemente estas innovaciones al entender que les aportan ventajas y eficiencia en los procesos; pues sin ese alineamiento, la transformación no resulta viable (Zott y Amit, 2007; Bueno, Rodríguez y Salmador, 2008).

Los ajustes en la plantilla y en las redes de oficinas de la banca española como consecuencia de la crisis, pero también del cambio tecnológico y de la reducción de costes que aporta la banca a distancia, ha creado también problemas de "exclusión financiera" ya que, en 2017, cerca del $48 \%$ de los municipios españoles y 1,13 millones de ciudadanos no tenían acceso a una oficina bancaria (Maudos 2017a) y esto supone también profundizar en la "brecha digital" de amplias capas de la sociedad española.

La idea de que las transformaciones radicales requieren reiniciar procesos o plantearlos de nuevo en su integridad empieza a cobrar sentido en muchas actividades del sector financiero; así, la ahora incipiente pero progresiva utilización de la tecnología blockchain redefinirá la intermediación financiera y eliminará actores muy asentados como las cámaras de compensación, los sistemas de liquidación, la gestión centralizada de órdenes y transacciones, los sistemas de transferencias, e incluso, la propia configuración de la moneda y su futura digitalización mediante criptoactivos. Se trata de una transformación sin precedentes, por la velocidad del cambio y por su dimensión global; una transformación que parece asimilarse al concepto de deconstrucción (Evans y Wurster, 1999).

La deconstrucción de los sistemas funciona como un proceso creativo o de innovación abierta (Chesbrough, 2003 y 2010) que reformula los cimientos de las organizaciones para pasar de la economía tradicional a la economía digital, 
situando a la tecnología en el centro de la actividad financiera, y convirtiendo a sus productos y servicios en simples "commodities".

Los usuarios de los servicios financieros serán más volátiles y menos leales por lo que ninguna entidad estará dispuesta a quedarse rezagada en su adaptación al cambio. Esos clientes demandarán una elevada calidad en los servicios, agilidad en las operaciones y traerán una nueva cultura financiera, con diferentes hábitos de consumo y de comportamiento tecnológico. Todo ello implicará también un adecuado equilibrio entre los procesos financieros tradicionales y los nuevos procesos al tiempo que será preciso establecer un sistema de transición que permita mantener a los clientes de siempre y adicionar a los nuevos clientes para que el proceso de transformación digital sea sostenible.

Por otra parte, hay que tener en cuenta el impacto que va a tener el denominado "open banking" como consecuencia de la aplicación de la directiva europea conocida como PSD2 ${ }^{5}$ o segunda directiva de servicios de pago, que obliga, desde comienzos de 2018, a que los bancos establezcan sistemas informáticos (conocidos como APIs ${ }^{6}$ ) que habiliten el acceso a los datos de los clientes por parte de otras entidades del sector fintech, siempre que éstas sean autorizadas por sus clientes lo que ha permitido acuñar el término de Apieconomía (Zachariadis y Ozcan, 2017).

En suma, son muchos y muy rápidos los cambios que acontecen en el sector financiero y la banca cooperativa no es ajena a ellos.

\section{Confección de la muestra y metodología}

Como se ha expuesto previamente, el objetivo principal de este trabajo es analizar la percepción de las cooperativas de crédito sobre el impacto que la transformación digital puede tener sobre sus entidades y sobre el modelo de relación con sus clientes y socios. Para ello, se ha confeccionado un cuestionario on line anonimizado de 20 preguntas mediante la plataforma Eval\&Go, dirigido a la población total de las 62 cooperativas de crédito españolas, canalizado a través de la Unión Nacional de Cooperativas de Crédito (UNACC) y del Grupo Cajamar. Se ha obtenido una muestra sustancial de 41 entidades (66\% de la población). El período de realización ha estado comprendido entre el 20 de marzo y 25 de abril de 2018. La ficha técnica se aporta en el anexo 1.

Las cuestiones preguntadas se dividieron en dos tipos (véase tabla 1). Por una parte, se recogieron datos sobre las características fundamentales de las entidades, como la dimensión, medida a través del activo total, número de empleados y oficinas; y la antigüedad de la entidad (para el caso de fusiones, se consideró desde el año de la fusión). Por otra parte, se realizaron preguntas sobre el grado de mejora y asimilación de la transformación digital, la percepción sobre ésta de socios y clientes, la posible existencia de brecha digital con respecto al resto del sector financiero o las modalidades de tecnologías que afectarían a la actividad. A su vez, también se analizó la percepción de las amenazas, fortalezas, debilidades y oportunidades (análisis DAFO); las valoraciones estratégicas y la cultura financiera

Second Payments Services Directive (PSD2).

Application Programming Interfaces (API). 
y tecnológica de los socios y clientes. Respecto al análisis, los resultados obtenidos de las respuestas se expondrán mediante un análisis gráfico y de tipo estadístico descriptivo, sustentado en la obtención de estadísticos comúnmente empleados.

Tabla. 1. Cuestionario.

\begin{tabular}{|l|l|}
\hline Preguntas & Contenido \\
\hline $1-4$ & Características de la entidad: tamaño y antigüedad. \\
\hline $5-12$ & $\begin{array}{l}\text { Grado de asimilación de la transformación digital, margen de mejora } \\
\text { y percepción de los clientes. } \\
\text { Existencia de brecha digital respecto al resto del sector bancario. } \\
\text { Percepción del impacto económico de la transformación digital. } \\
\text { Tipo de tecnologías que más afectan a la actividad. } \\
\text { Intensidad de la competencia prevista de diferentes actores. } \\
\text { Obstáculos para la transformación digital. }\end{array}$ \\
\hline $13-16$ & $\begin{array}{l}\text { Principal fortaleza, debilidad, amenaza y oportunidad (próximos 5 } \\
\text { años). }\end{array}$ \\
\hline $17-18$ & Estrategia para los próximos 5 años y percepciones sobre el futuro. \\
\hline 19 & Cultura financiera y tecnológica de socios y clientes. \\
\hline 20 & Comentarios opcionales. \\
\hline
\end{tabular}

Fuente: elaboración propia.

\section{Resultados del análisis}

\section{Caracteristicas de las entidades:}

Las primeras cuatro preguntas del cuestionario fueron relativas a las características de las entidades encuestadas, con el fin de ofrecer una visión de la dimensión y antigüedad de las mismas. A partir de las respuestas obtenidas, se elaboró la tabla 2, que aúna el número de observaciones, la media aritmética, la desviación típica, el máximo, el mínimo y los percentiles 25, 50 y 75 de las variables: activo total, empleados, número de oficinas y antigüedad. Por tanto, de las entidades que componen la muestra, es posible concretar que presentan una gran heterogeneidad en términos de dimensión, como se deriva de la desviación típica obtenida del activo total, empleados y número de oficinas, si bien el volumen medio de activo total es de 3.487 (millones $€$ ) y el $75 \%$ de las entidades presentan un valor del activo inferior a 2.798 (millones $€$ ). En el caso del número de empleados, la entidad con menor dimensión laboral cuenta con sólo cuatro empleados, mientras que en el otro extremo se encuentra una entidad que alcanza los 4.418 empleados. No obstante, el $75 \%$ de las entidades encuestadas tiene menos de 400 empleados y la mitad de éstas no alcanza los 50 empleados. Respecto al número de oficinas, la cantidad promedio está en torno a las 100, aunque el $50 \%$ de las entidades dispone de menos de 13 oficinas. Por último, se trata de entidades con una antigüedad media aproximada de 46 años, teniendo la más joven cinco años y la más antigua 101 años. 
Tabla. 2. Respuestas a preguntas 1-4.

\begin{tabular}{|l|l|r|r|r|r|r|r|r|}
\hline Var & Obs & Media & $\begin{array}{l}\text { Desv } \\
\text { Típica }\end{array}$ & Máx & Mín & Perc25 & Perc50 & Perc75 \\
\hline $\begin{array}{l}\text { Activo Total } \\
\text { (mill } € \text { ) }\end{array}$ & 41 & 3.487 & 8.038 & 44,604 & 20 & 114 & 519,027 & 2.798 \\
$\begin{array}{l}\text { Empleados } \\
\text { No Oficinas }\end{array}$ & 41 & 447,37 & 863,60 & 4.418 & 4 & 23 & 50 & 400 \\
$\begin{array}{l}\text { Antigüedad } \\
\text { (años) }\end{array}$ & 38 & 45,76 & 28,90 & 101 & 5 & 15,50 & 50,50 & 59,25 \\
\hline
\end{tabular}

Fuente: elaboración propia a partir de los resultados del cuestionario.

Transformación digital en las cooperativas de crédito españolas:

Una vez realizada la aproximación a las características de la muestra, en este punto se mostrarán los resultados derivados de las preguntas restantes, centradas en las percepciones sobre el impacto de la transformación digital (gráficos 1 a 8 y tabla 4), principal fortaleza, debilidad, amenaza y oportunidad percibidas (tabla 3), el futuro de la actividad bancaria (gráfico 9) y el grado de cultura financiera y tecnológica de socios y clientes (gráfico 10). Téngase en cuenta que las valoraciones se han estructurado en la escala de 0 (nada) a 5 puntos (mucho).

En este sentido, el gráfico 1 permite visualiza el margen de mejora percibido por las entidades en términos de transformación digital, tanto en la operativa como en los procesos de gestión interna. Así, en general, los resultados superan los 3 puntos, alcanzando en muchos casos los 4 puntos, lo que explica unos valores medios de 3,53 y 3,63 puntos, respectivamente. Teniendo en cuenta que el valor máximo es 5, representando mucho margen de mejora, estas puntuaciones indican que las entidades analizadas consideran estar aún a la zaga en términos de transformación digital.

Gráfico. 1. En relación con la transformación digital, ¿cuál cree que es el margen de mejora de su entidad? Indique sobre la escala creciente de 0 (nada) a 5 (mucho).

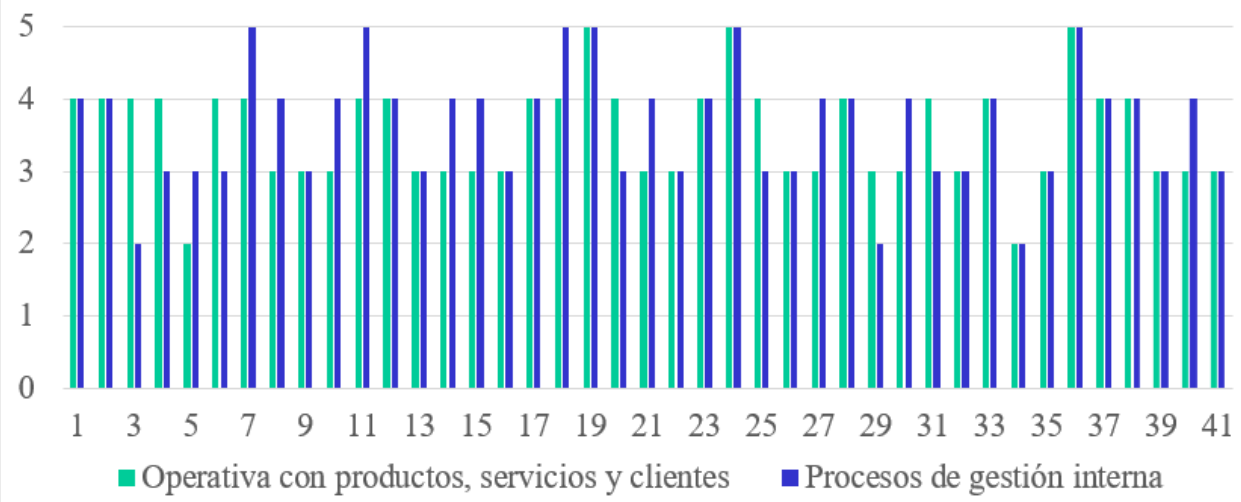

Fuente: elaboración propia a partir de los resultados del cuestionario. Valores medios: 3,53 y 3,63 , respectivamente. 
A su vez, estos datos pueden explicarse al tener en cuenta el bajo grado de asimilación de dicha transformación digital entre algunos de los componentes que conforman las entidades (véase gráfico 2). Concretamente, tal asimilación se percibe más bien baja por parte del Consejo Rector y la presidencia (valor medio: 2,9 ) y socios y clientes (valor medio: 2,8 ), respecto a los empleados (valor medio: 3,41 ) y la Dirección General y equipo directivo (valor medio: 3,63 ).

Gráfico. 2. ¿Cuál considera que es el grado de asimilación actual de la transformación digital en relación con los siguientes componentes de su entidad? Indique sobre la escala creciente de 0 (nada) a 5 (mucho).

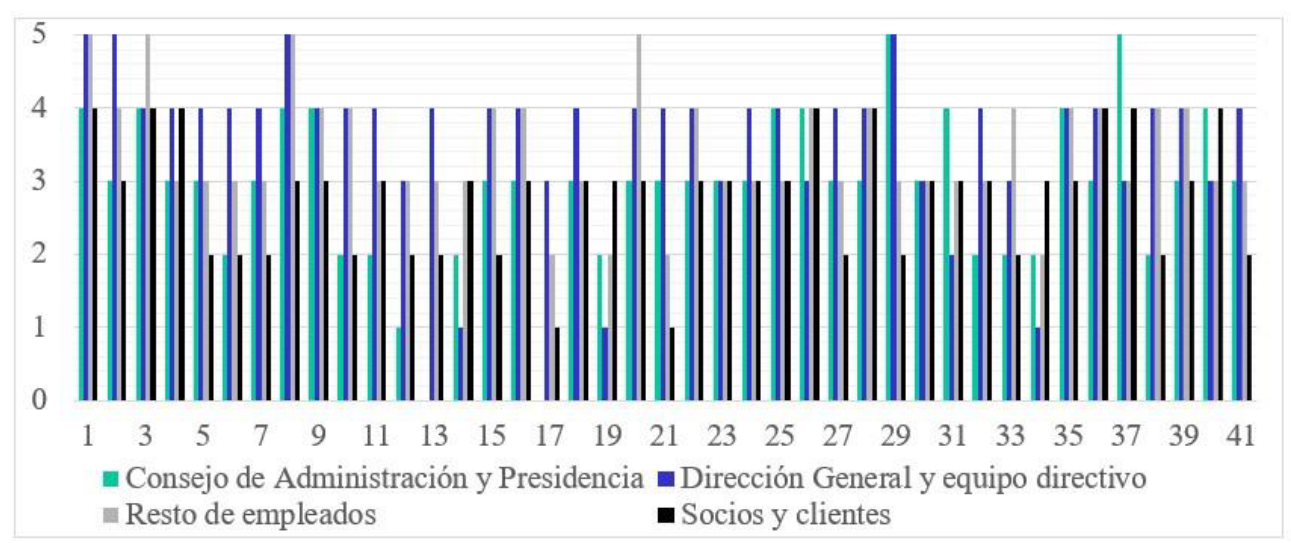

Fuente: elaboración propia a partir de los resultados del cuestionario. Valores medios: 2,9, $3,41,3,63$ y 2,8 , respectivamente.

Sin embargo, respecto a la visión percibida de los componentes externos a la entidad sobre el grado de adaptación tecnológica de la misma a sus necesidades, el gráfico 3 muestra que la mayor parte de las respuestas otorgan al menos un 3 de valoración, es decir, el primero de los tres valores más altos que puede tomar la medida. Por tanto, si bien se percibe un grado de asimilación de la transformación digital de los socios y clientes inferior al que se observa en los componentes directamente vinculados a la entidad (gráfico 2), se considera que los primeros perciben adecuadamente la adaptación tecnológica llevada a cabo por la organización. 
Gráfico. 3. Valore sobre la siguiente escala cómo considera que sus socios y clientes perciben a su entidad en términos de adaptación tecnológica a sus necesidades de productos y servicios. Escala creciente de 0 (nada) a 5 (mucho).

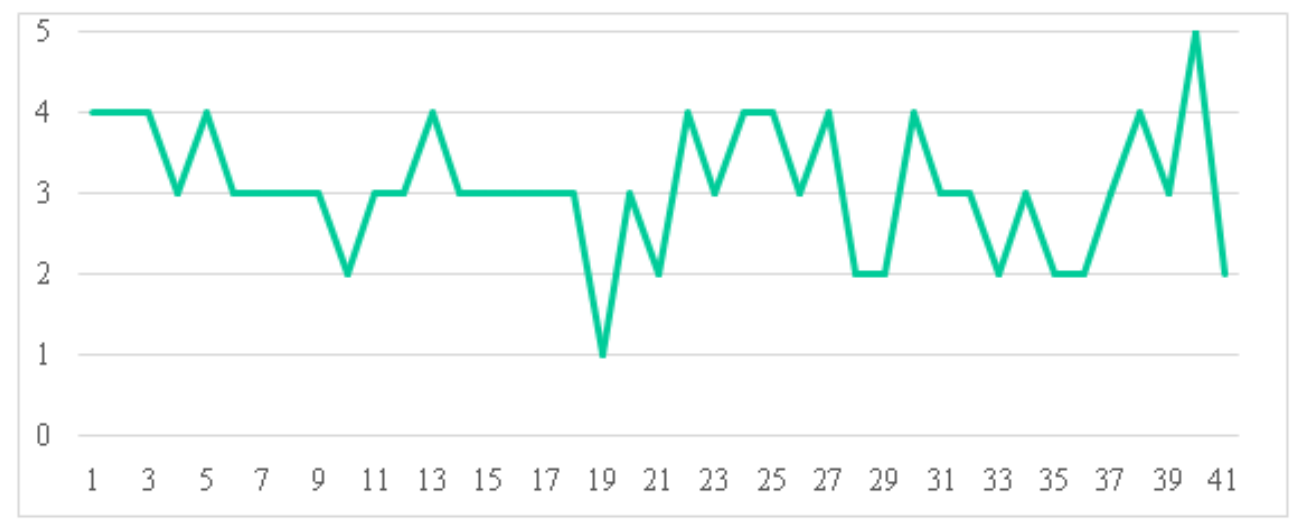

Fuente: elaboración propia a partir de los resultados del cuestionario. Valor medio: 3,03.

A su vez, con el fin de ofrecer una medida de la percepción de adaptación tecnológica del sector respecto al resto del ámbito bancario, el gráfico 4 muestra las respuestas relativas a la pregunta sobre la existencia de brecha digital entre ambos conjuntos. Tal como se observa, aunque la mayoría de las entidades afirmó la presencia de tal brecha, lo cierto es que muchas consideran que ésta no es amplia.

Gráfico. 4. Indique sobre la siguiente escala si considera que en su sector existe brecha digital con respecto al resto del sector bancario. Escala creciente de 0 (nada) a 5 (mucho).

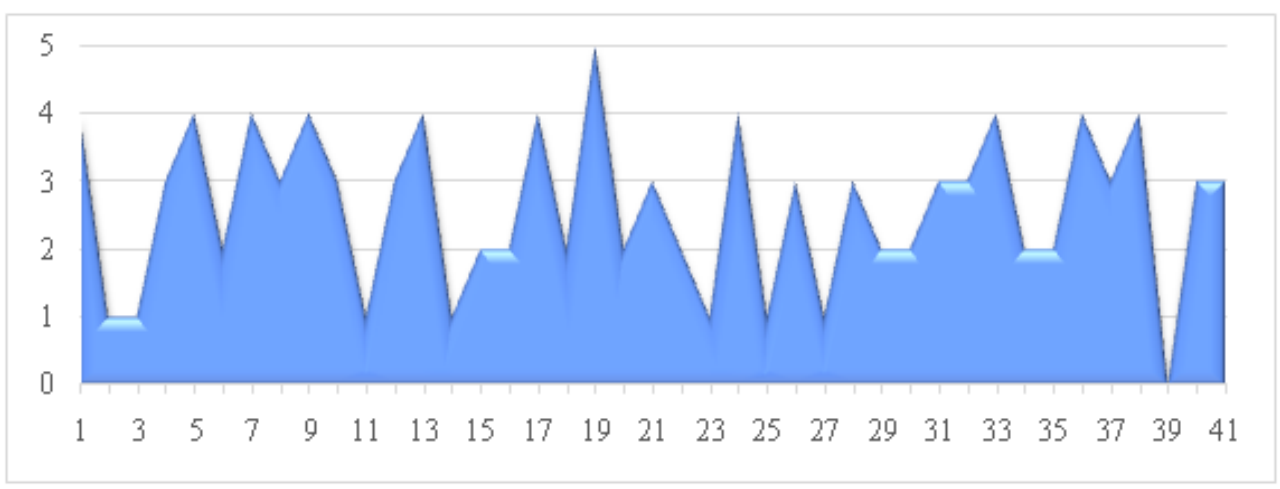

Fuente: elaboración propia a partir de los resultados del cuestionario. Valor medio: 2,63.

Por otra parte, se considera imprescindible una reflexión sobre la repercusión de la transformación digital más allá del entorno específico de la entidad, razón por la que se incluye la pregunta que se expone en el gráfico 5. 
Gráfico. 5. Indique sobre la siguiente escala cómo se percibe desde su entidad el impacto que está teniendo y que puede tener la transformación digital de la economía. Escala creciente de 0 (nada) a 5 (mucho).

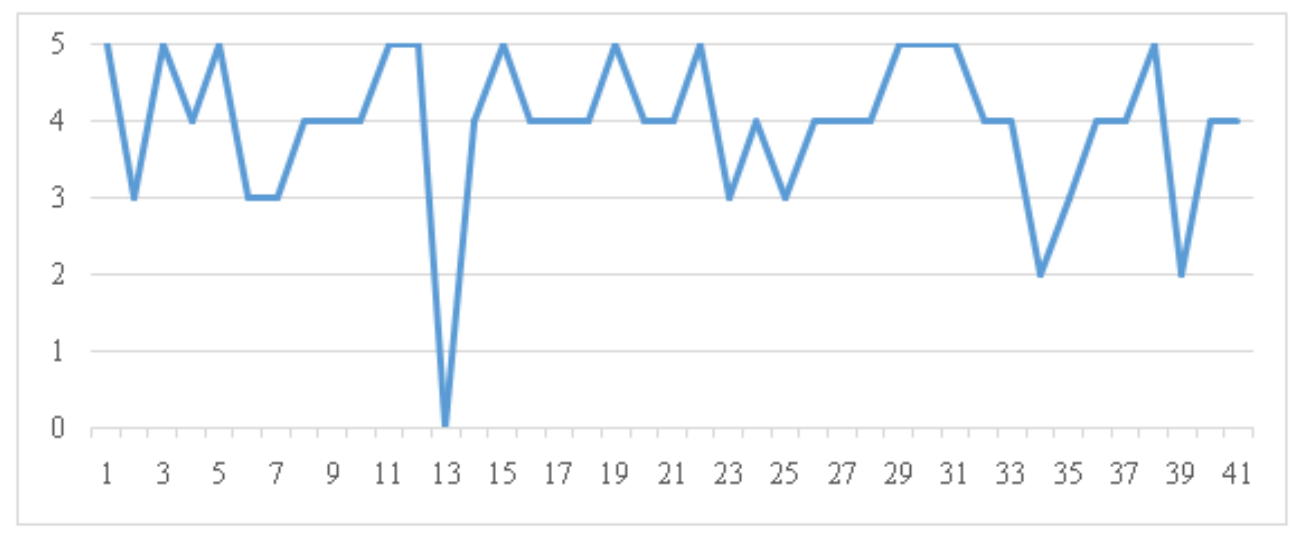

Fuente: elaboración propia a partir de los resultados del cuestionario. Valor medio: 4,05.

En esta línea, las respuestas obtenidas están concentradas entre los valores 3 y 5 , con mayor número de afirmaciones entre 4 y 5 , lo que indica que las empresas encuestadas estiman que la transformación digital de la economía está teniendo un efecto significativo en la actividad económica.

Realizada una valoración global del grado de mejora y asimilación de la transformación digital y su impacto, a continuación se reflexionará sobre la importancia de las diferentes tecnologías para la actividad de las entidades encuestadas (véanse gráficos 6.1 a 6.3). Observando las respuestas distribuidas en los tres gráficos, la puntuación más alta la recibe el big data (valor medio: 4,07) seguida del cloudcomputing (valor medio: 3,34), el blockchain (valor medio: 3,33) y la inteligencia artificial (valor medio: 3,32). Por contra, la valoración más baja fue asignada a la realidad aumentada y virtual (valor medio: 2,19), criptomonedas (valor medio: 2,27) e internet de las cosas (valor medio: 2,29), respectivamente. Por tanto, el big data representa la tecnología que más y con mayor importancia puede condicionar la actividad de las entidades participantes, encontrándose en el otro extremo la realidad aumentada y virtual. 
Gráfico. 6.1. Indique cuáles de las siguientes tecnologías y con qué grado de importancia considera que pueden afectar más a su actividad como entidad financiera. Indicarlo sobre la siguiente escala creciente de 0 a 5.

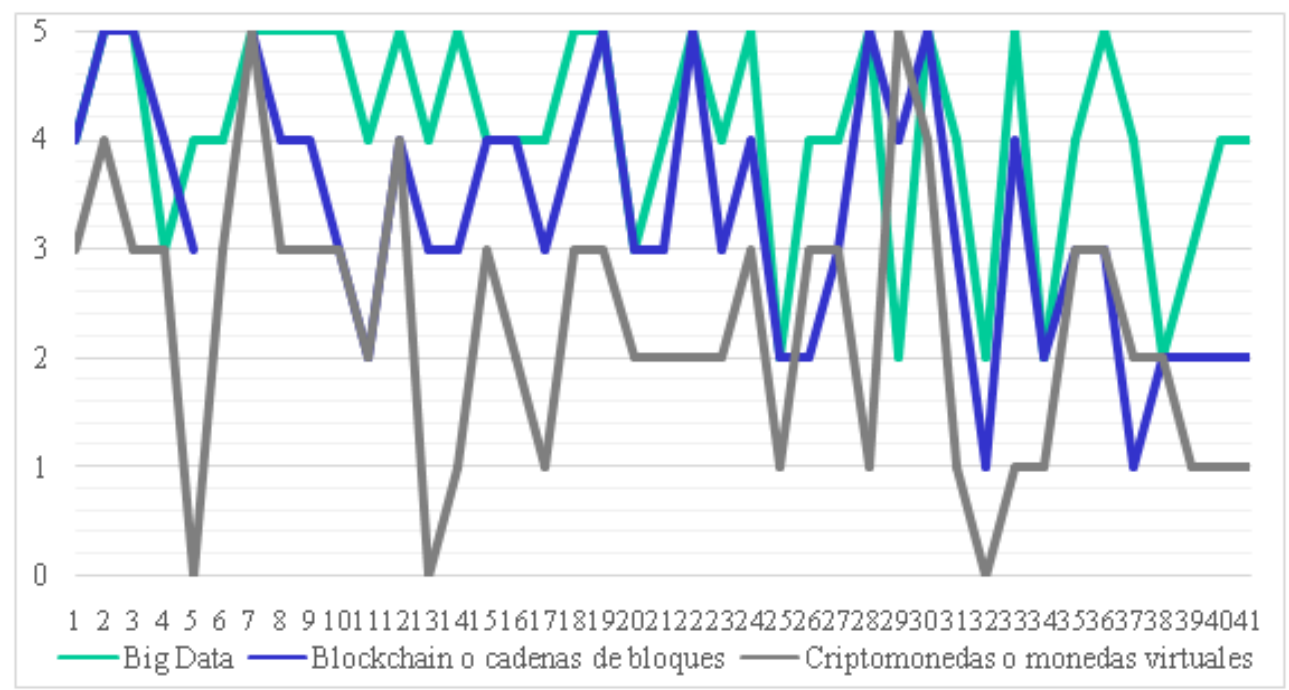

Fuente: elaboración propia a partir de los resultados del cuestionario. Valores medios: 4,07, 3,33 y 2,27 , respectivamente.

Gráfico. 6.2. Indique cuáles de las siguientes tecnologías y con qué grado de importancia considera que pueden afectar más a su actividad como entidad financiera. Indicarlo sobre la siguiente escala creciente de 0 a 5.

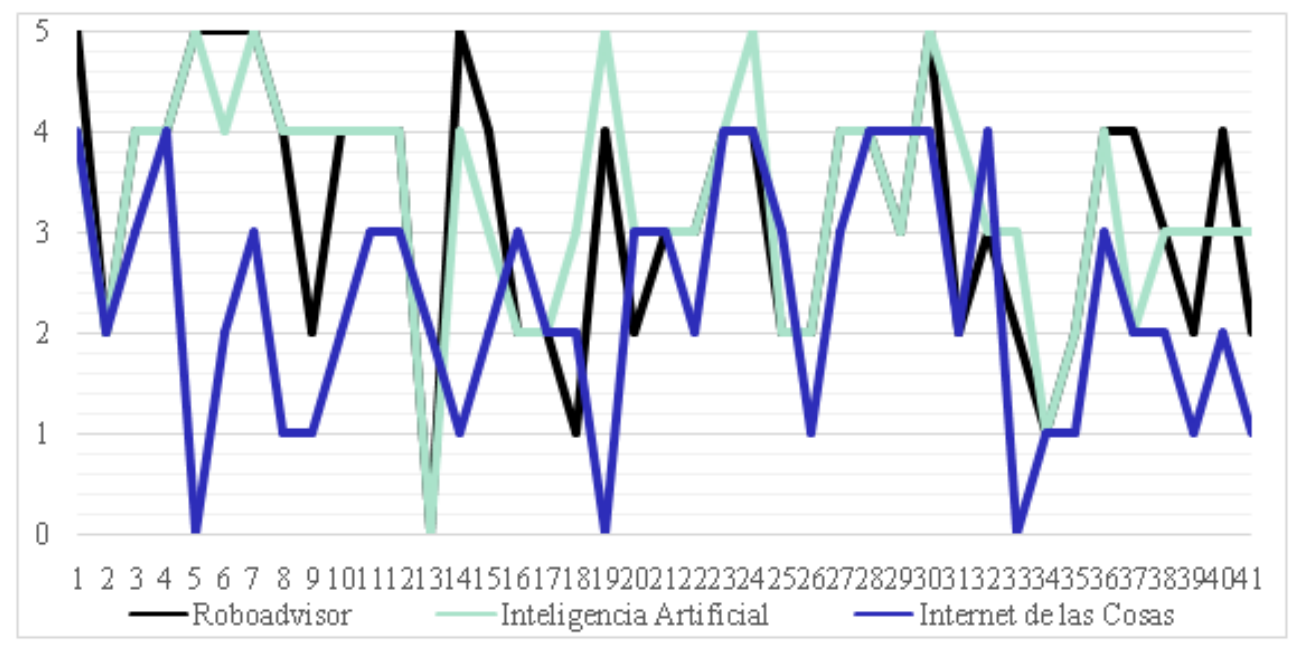

Fuente: elaboración propia a partir de los resultados del cuestionario. Valores medios: 3,19, 3,32 y 2,29 , respectivamente. 
Gráfico. 6.3. Indique cuáles de las siguientes tecnologías y con qué grado de importancia considera que pueden afectar más a su actividad como entidad financiera. Indicarlo sobre la siguiente escala creciente de 0 a 5.

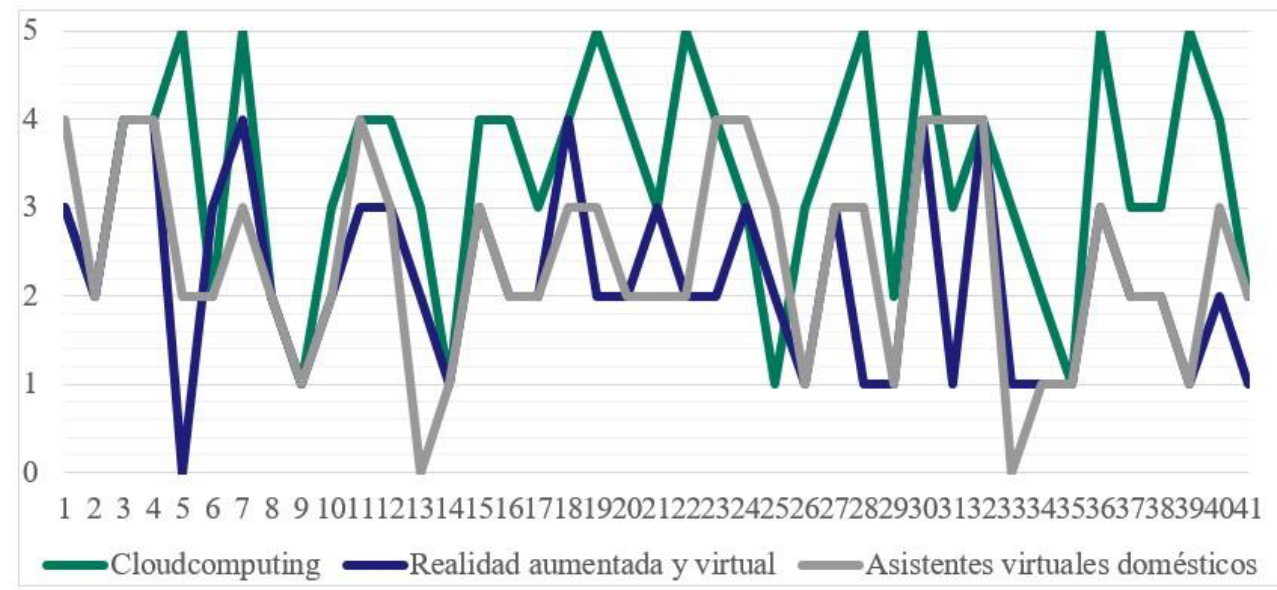

Fuente: elaboración propia a partir de los resultados del cuestionario. Valores medios: 3,34, 2,19 y 2,41 , respectivamente.

Unido a lo anterior, se considera necesario aportar una perspectiva de la intensidad de la competencia, comparando entre competidores tradicionales y aquellos cuya estructura es de base tecnológica (véanse gráficos 7.1 y 7.2).

Gráfico. 7.1. En relación con la competencia en su sector, indique el grado de intensidad de la competencia que previsiblemente tendrá su entidad procedente de los siguientes actores durante los próximos 5 años.

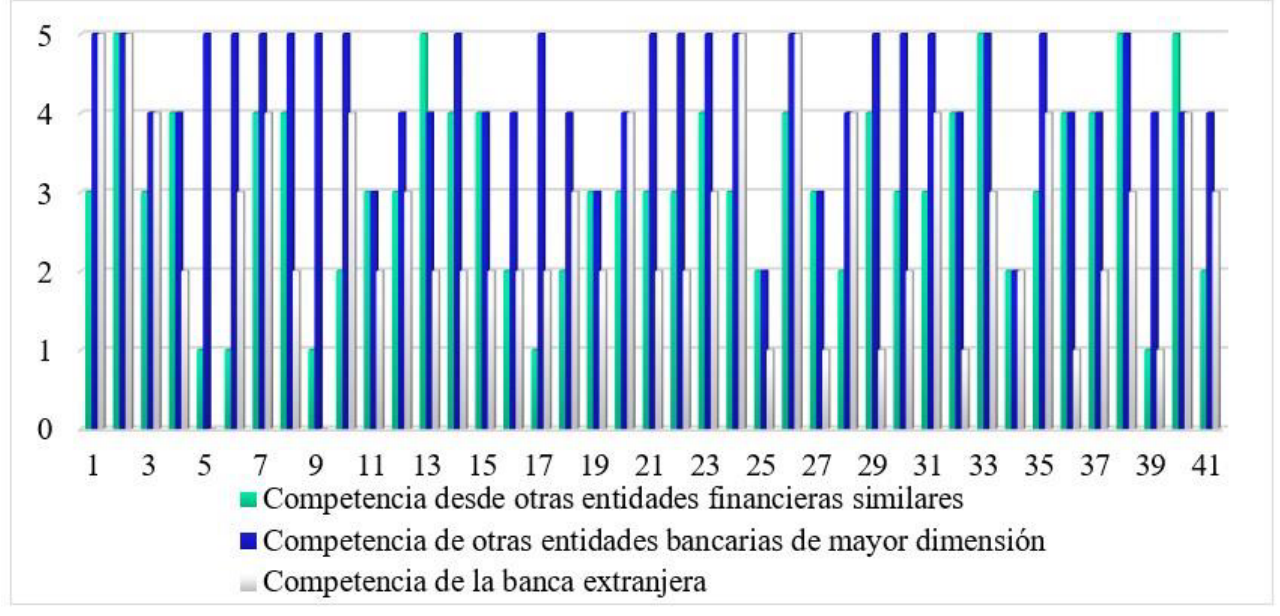

Fuente: elaboración propia a partir de los resultados del cuestionario. Valores medios: 3,1 , $4,34,2,61$, respectivamente. 
Gráfico. 7.2. En relación con la competencia en su sector, indique el grado de intensidad de la competencia que previsiblemente tendrá su entidad procedente de los siguientes actores durante los próximos 5 años.

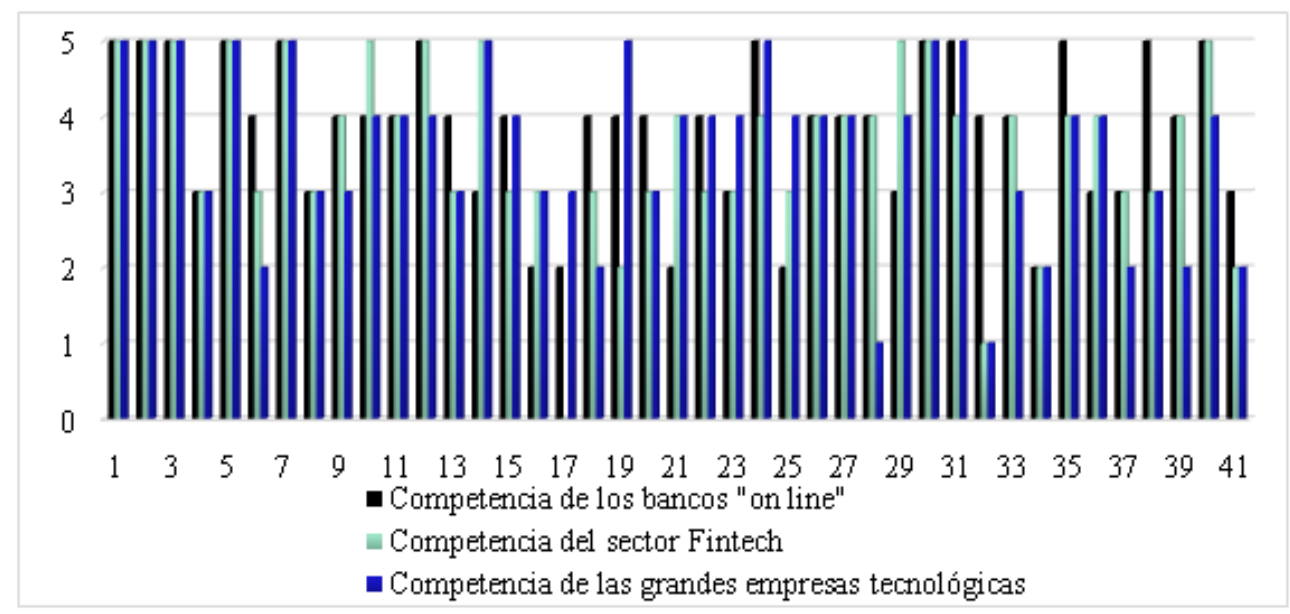

Fuente: elaboración propia a partir de los resultados del cuestionario. Valores medios: 3,85, 3,63 y 3,58 , respectivamente.

Así, los resultados avalan que, si bien la competencia que se prevé más intensa en los próximos cinco años es la representada por las entidades bancarias de mayor dimensión (valor medio: 4,34), los siguientes competidores que más preocupan a las cooperativas de crédito estudiadas son aquellos cuyo modelo de negocio se sustenta en la tecnología, como los bancos on line, el sector fintech y las grandes empresas tecnológicas (siendo las puntuaciones medias: 3,85, 3,63 y 3,58, respectivamente).

Por otra parte, resulta imprescindible tener en cuenta los posibles obstáculos que pueden dificultar la evolución de la transformación digital (gráfico 8). A este respecto, las respuestas obtenidas son contundentes: 30 de las 41 entidades analizadas coinciden en que la inversión requerida obstaculiza la transformación digital (concretamente, el 73,17\%), tratándose, por tanto, de la barrera que ha generado mayor consenso. Al observar los resultados para el resto de obstáculos, destacan dos conjuntos: aquellos cuya proporción de respuestas oscila en el rango $34-39 \%$ y los que no alcanzan el 20\% de las respuestas. Entre los primeros se encuentran la dificultad de adaptación al cambio de socios y clientes $(39,02 \%)$, la resistencia al cambio $(36,59 \%)$ y la falta de recursos humanos $(34,15 \%)$. Entre los segundos están falta de asesoramiento o formación y otros obstáculos (ambos con un $19,51 \%$ ) y la no necesidad de este cambio tecnológico al no requerirlo socios y clientes $(17,07 \%)$. 
Gráfico. 8. Indique cuáles pueden ser los principales obstáculos para evolucionar en la transformación digital de su entidad.

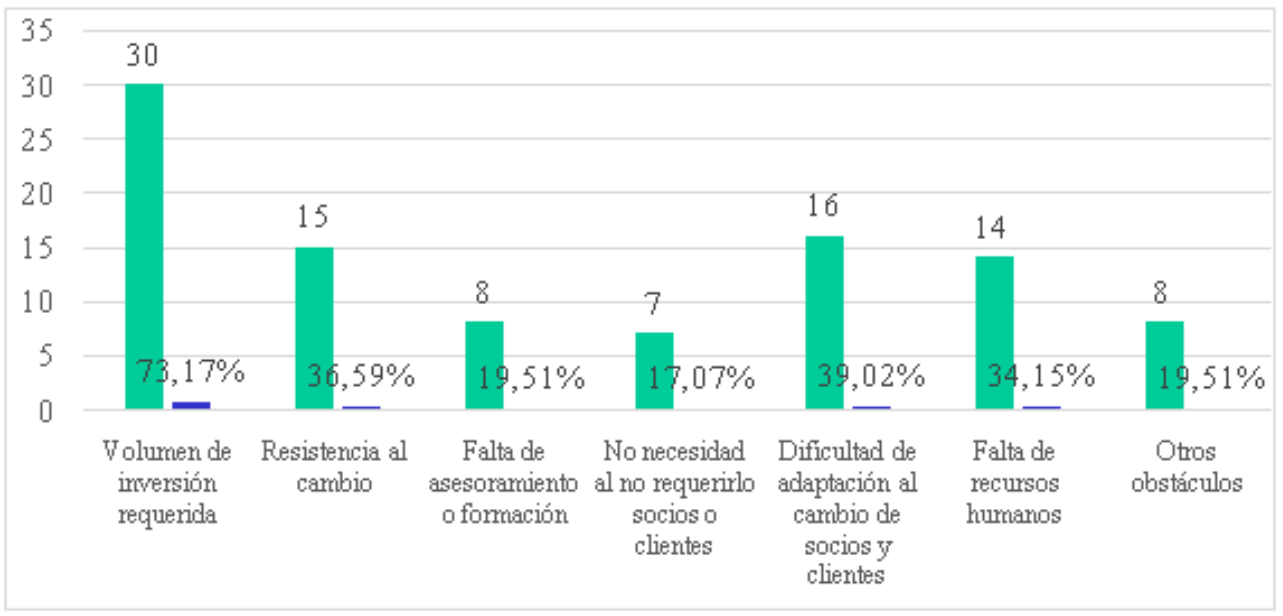

Fuente: elaboración propia a partir de los resultados del cuestionario.

Adicionalmente, con el fin de aportar una perspectiva estratégica al análisis, las siguientes tablas reflejan las respuestas sobre la principal fortaleza, debilidad, amenaza y oportunidad percibidas (tabla 3) y la aplicación tecnológica considerada más relevante (tabla 4), en ambos casos tomando como referencia un horizonte a medio plazo.

Comenzando por la tabla 3, dado que se trata de información cualitativa, en ésta se aportan las cuestiones más veces señaladas en orden descendente. Respecto a la fortaleza, la cercanía y la proximidad al cliente han sido las más mencionadas, siendo la capacidad tecnológica la tercera mayor citada, concretamente por seis entidades. En cuanto a la debilidad, las que más preocupan a las entidades encuestadas son el tamaño y la resistencia al cambio (citadas por ocho y siete empresas, respectivamente), siendo la eficiencia la que ocupa la tercera posición. Si observamos la amenaza más señalada, llama la atención que la competencia asociada a la transformación digital es el ítem que mayor consenso ha generado entre las cooperativas analizadas, al indicarla 25 de las 41 empresas encuestadas. Por tanto, ello viene a ratificar lo observado en el gráfico 7.2, en el que se refleja que las cooperativas participantes en este estudio esperan una competencia más intensa en los próximos cinco años de las entidades financieras de base tecnológica que de otras entidades financieras similares o de la banca extranjera. Además, la percepción de esta amenaza puede estar condicionada por la consideración del amplio margen de mejora aún existente en el proceso de transformación digital iniciado por estas entidades (véase gráfico 1). Por último, la principal oportunidad que generó mayor acuerdo entre las empresas del estudio fue el uso de nuevas tecnologías, afirmación realizada por 12 de éstas, lo cual viene a reafirmar la importancia de la transformación digital como fuente potencial de ventaja competitiva. Referente a la información de la tabla 4, ésta viene a constatar la 
importancia otorgada al big data como la aplicación tecnológica que mayor ventaja competitiva puede ofrecer en el futuro, en línea con lo observado en el gráfico 6.1.

Tabla. 3. Indique la principal FORTALEZA/DEBILIDAD/AMENAZA/OPORTUNIDAD de su entidad en el horizonte de los próximos 5 años, es decir, el aspecto en el que se considera más fuerte/vulnerable/amenazado o dónde puede actuar para mejorar, pudiendo añadir más de uno.

\begin{tabular}{|l|l|l|l|}
\hline $\begin{array}{l}\text { FORTALEZA } \\
\text { (39 Respuestas) }\end{array}$ & $\begin{array}{l}\text { DEBILIDAD } \\
\text { (36 Respuestas) }\end{array}$ & $\begin{array}{l}\text { AMENAZA } \\
\text { (37 Respuestas) }\end{array}$ & $\begin{array}{l}\text { OPORTUNIDAD } \\
\text { (35 Respuestas) }\end{array}$ \\
\hline $\begin{array}{l}\text { Cercanía (10) } \\
\text { Proximidad (8) }\end{array}$ & $\begin{array}{l}\text { Tamaño (8) } \\
\text { Resistencia apacidad } \\
\text { cambio (7) } \\
\text { tecnológica (6) }\end{array}$ & $\begin{array}{l}\text { Competencia, sobre } \\
\text { todo asociada a la } \\
\text { transformación } \\
\text { Conocimiento (4) } \\
\text { Confianza (3) }\end{array}$ & $\begin{array}{l}\text { Nuevas tecnologías } \\
\text { (12) }\end{array}$ \\
$\begin{array}{l}\text { Modelo de tecnología } \\
\text { cooperativo (3) }\end{array}$ & Regulación (2) & $\begin{array}{l}\text { Especialización en } \\
\text { segmentos } \\
\text { determinados (8) } \\
\text { Cercanía al cliente } \\
\text { (5) de mercado }\end{array}$ & Agresividad \\
comercial (2) & Concentración (2) & & \\
\hline
\end{tabular}

Fuente: elaboración propia a partir de los resultados del cuestionario.

Tabla. 4. ¿Cuál sería la aplicación tecnológica que podría aportar más valor o estrategia competitiva para su entidad en los próximos 5 años?

\begin{tabular}{|l|c|}
\hline APLICACIONES MÁS CITADAS & No VECES QUE SE CITA (32 Respuestas) $^{\text {B }}$ \\
\hline Big Data & 7 \\
\hline Banca Móvil & 4 \\
\hline
\end{tabular}

Fuente: elaboración propia a partir de los resultados del cuestionario.

Para finalizar, los dos gráficos siguientes complementarán la información anterior mediante una visión de la percepción futura del modelo bancario actual (gráfico 9) y de la cultura financiera y tecnológica de socios y clientes (gráfico 10). Tal como se deriva del gráfico 9 , en un horizonte de 10 años se percibe bastante incertidumbre respecto al modelo de actividad bancaria existente en la actualidad. Concretamente, más de la mitad de las cooperativas respondieron concebir ese futuro regular (el 51,22\%), lo que, unido a las que afirmaron un contexto de adversidad (12,20\%), implican que 26 de las 41 empresas estiman cambios importantes en el tipo de actividad bancaria actual. En el otro extremo, sólo una empresa se mostró optimista al esperar un futuro muy bueno, mientras que las 14 restantes lo valoraron como bueno. 
Gráfico. 9. ¿Cómo percibe el futuro del modelo actual de actividad bancaria en un horizonte de 10 años?.

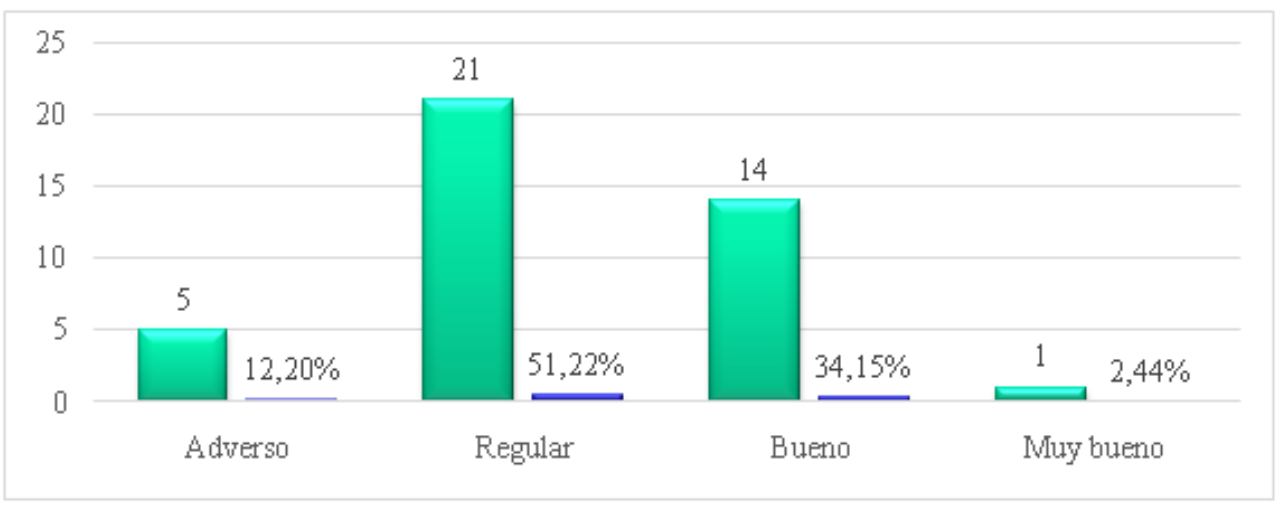

Fuente: elaboración propia a partir de los resultados del cuestionario.

Si se toma en consideración el grado de cultura financiera y tecnológica de los componentes externos a la entidad, es decir, de socios y clientes, el gráfico 10 muestra que las cooperativas encuestadas otorgan una puntuación media inferior a 3, siendo la peor valoración para el grado general de cultura tecnológica (valor medio: 2,51). Ello puede explicar la percepción de que los socios y clientes son los componentes de la entidad que menos han asimilado la transformación digital del sector (véase gráfico 2). Sin embargo, las respuestas obtenidas muestran optimismo respecto al papel de la entidad en el fomento de dicha cultura financiera y tecnológica de socios y clientes, al considerar que puede contribuir en esta dirección, como se deduce de las puntuaciones medias recibidas respecto a las dos últimas preguntas: 3,8 para el caso de la cultura financiera y 3,63 si se trata de la cultura tecnológica. 
Gráfico. 10. Y, por último, en relación con la cultura financiera y tecnológica de sus socios y clientes, indique, sobre la escala creciente de 0 (nada) a 5 (mucho), las siguientes cuestiones.

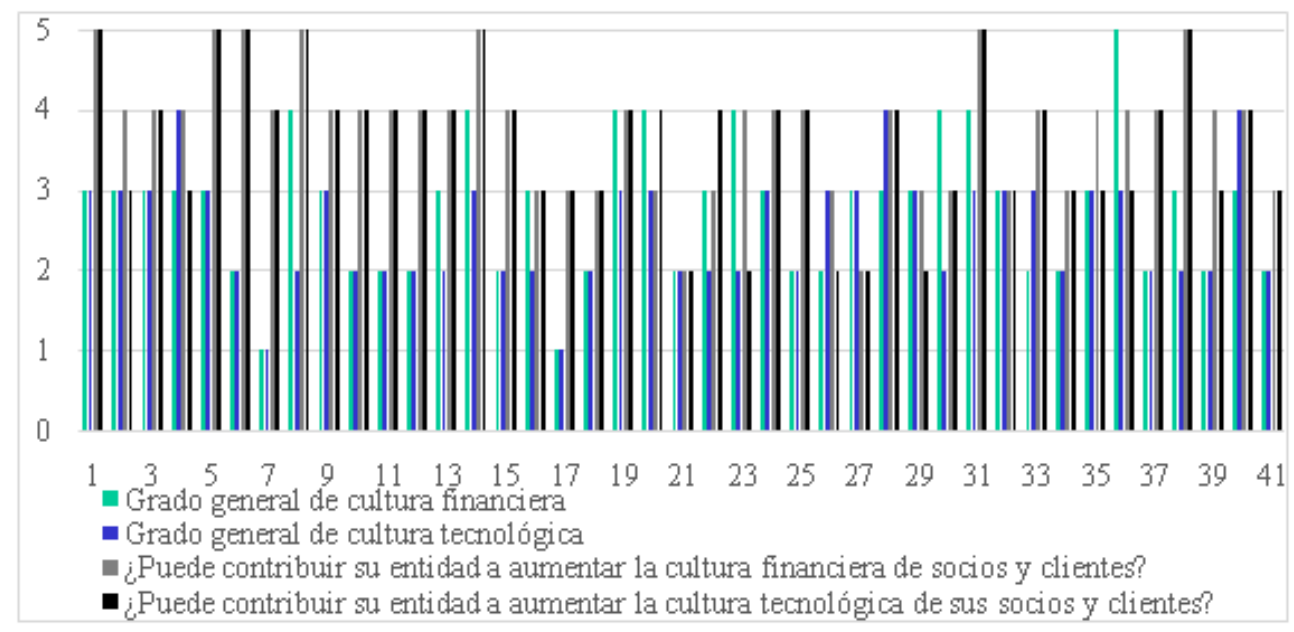

Fuente: elaboración propia a partir de los resultados del cuestionario. Valores medios: 2,78, $2,51,3,8$ y 3,63 , respectivamente.

Como cierre a este punto, se considera necesario aunar las concreciones fundamentales derivadas del análisis realizado. Por una parte, las cooperativas de crédito encuestadas coinciden, en general, en la importancia de la transformación digital como ventaja competitiva, en un contexto en el que dicho desafío está generando un impacto económico significativo, marcado por el potencial recrudecimiento de la competencia proveniente de empresas tecnológicas en un futuro cercano. Por otra, dichas entidades son conscientes del amplio camino que queda aún por recorrer en términos de transformación digital, habiendo obstáculos importantes como la inversión requerida o la dificultad de adaptación al cambio de socios y clientes, los cuales aún adolecen de una adecuada cultura tecnológica y representan los grupos de interés que menos han asimilado la transformación digital del sector.

\section{Conclusiones}

La evolución exponencial de la tecnología durante los últimos años y su aplicación en el ámbito de la economía está conduciendo a una transformación digital sin precedentes, tanto en las empresas como en la sociedad. Su particular aplicación en el ámbito financiero, particularmente mediante el uso de big data, de la computación en la nube, o del asesoramiento y atención robotizada a los clientes, así como la próxima irrupción de las aplicaciones de la tecnología de cadenas de bloques (blockchain), supone una clara disrupción para el sector financiero tradicional, que ahora percibe una triple competencia: la propia y habitual entre 
entidades de su sector; la nueva potencial competencia del sector fintech, y la amenazante competencia de las grandes empresas tecnológicas.

Por esta razón, resulta muy oportuno analizar cómo se percibe este complejo y disruptor escenario competitivo desde el punto de vista de entidades bancarias con actividad tradicional, cuya principal ventaja competitiva es la cercanía física a sus usuarios y su presencia y fuerte conocimiento del ámbito territorial en el que operan, fundamentado en la capilaridad de su red de oficinas.

Mediante un amplio cuestionario que ha tenido una elevada tasa de respuesta, gracias a la colaboración de la UNACC y del Grupo Cajamar, se ha podido realizar un primer estudio, de ámbito nacional, pionero en esta cuestión; y del que se han extraído interesantes resultados sobre los que se podrá profundizar en posteriores investigaciones.

El sector de la banca cooperativa española es un sector muy heterogéneo en dimensión que, sin embargo, comparte un mismo modelo de negocio y que, según los resultados de este trabajo, reconoce que tiene, al igual que muchos de sus competidores, un apreciable camino por recorrer en materia de transformación digital; si bien, perciben igualmente que su adaptación puede ser ya incluso superior a la que asimila una amplia proporción de sus propios socios y clientes.

Las entidades analizadas perciben una ligera brecha en esa transformación digital frente a sus competidores los bancos; y son conscientes del fuerte impacto de esta transformación en la actividad económica, reconociendo que algunas tecnologías van a tener mayor protagonismo en su sector de actividad, como es el caso de big data, la computación en la nube y la novedosa tecnología blockchain, frente a otras tecnologías.

Estas entidades prevén que la competencia durante los próximos años procederá de las grandes entidades bancarias, pero también, de la banca on line, del más reciente sector fintech y de las grandes empresas tecnológicas, destacando éstas últimas como amenaza ya cercana.

A pesar de que se sienten fuertes en cercanía y proximidad en la relación con el cliente, perciben debilidad por razón de su dimensión y también por la resistencia al cambio en la transformación digital, tanto dentro de sus organizaciones, como por parte de algunos sectores de su clientela.

Al igual que el conjunto del sector bancario internacional debate actualmente sobre el futuro de su modelo de negocio, las entidades analizadas en este trabajo muestran un sentimiento de incertidumbre y cierta preocupación por el futuro del modelo bancario actual y su sostenibilidad en el futuro.

Por otra parte, estas entidades, que consideran que su evolución tecnológica es, a veces, más rápida que el propio grado de asimilación que pueden hacer de ella sus socios y clientes, estiman que pueden jugar un papel importante en el fomento de una cultura financiera de base digital que ayude a la transformación digital del sector y de la sociedad, que ayude a definir su viabilidad competitiva en este contexto de acelerada transformación digital, tanto en el sector financiero como en el conjunto de la sociedad.

En futuras líneas de investigación se podrán analizar los elementos que podrán actual como catalizadores de la transformación digital de la banca cooperativa y su coexistencia con su contrastado modelo de banca intensivo en la proximidad a sus socios y clientes y extensivo en la capilaridad de su red comercial. 


\section{Referencias bibliográficas}

Akkizidis, I. y Stagars, M. (2016) Marketplace lending, Financial Analysis, and the Future of credit: Integration, Profitability, and risk management. Estados Unidos: John Wiley Sons Inc.

Bueno, E.; Rodríguez Antón, J. M. y Salmador, M. P. (2008) Knowledge creation as a dynamic capability: implications for innovation and organizational design. International Journal of Technology Management, Vol. 41, $\mathrm{N}^{\mathrm{o}} 1 / 2, \quad \mathrm{pp}$. 155-168. https://doi.org/10.1504/IJTM.2008.015989.

Carbó, S. y Rodríguez Fernández, F. (2017) La banca española en Europa: de la transición a la acción. Cuadernos de Información Económica, № 257, marzo, pp. 1-9.

Carbó, S. y Rodríguez-Fernández, F. (2016) Otro giro en la reestructuración bancaria. Cuadernos de Información Económica, $\mathrm{N}^{\mathrm{o}}$ 252, pp. 84-97.

Carbó, S. y Rodríguez-Fernández, F. (2014) El sector bancario español ante un nuevo paradigma: Reconsideración del tamaño. Papeles de Economía Española, Número extraordinario: Nuevos negocios bancarios, pp. 19-20.

Chesbrough, H. (2003) Open Innovation: The new imperative for creating and profiting from technologies. Cambridge-MA: Harvard Business School Press.

Chesbrough, H. (2010) Business model innovation, opportunities and barriers. Long Range Planning, No 43, pp. 354-363. https://doi.org/10.1016/j.lrp.2009.07.010.

Chishti, S. y Barberis, J. (2016) The Fintech book: The financial technology handbook for investors, entrepreneurs and visionaries. Chichester, West Sussex: John Wiley \& Sons.

EACB-European Asociation of Cooperative Banks (2014) Road Map for Co-operative Banks. Bruselas: EACB.

Evans, Ph. y Wurster, Th. S. (1999) Blown to Bits. Boston: Harvard Business School Press.

Giesen, E.; Riddleberger, E.; Christensen, R. y Bell, R. (2010) When and how to innovate your business model. Strategy and Leadership, Vol. 38, $\mathrm{N}^{\mathrm{o}} 4$, pp. 17-26. https://doi.org/10.1108/10878571011059700.

Gutiérrez, M.; Palomo, R. y Romero, M. (2012) La expansión territorial como factor motivador de la reestructuración del sistema financiero español: El caso de las cajas de ahorros y las cooperativas de crédito. REVESCO. Revista de Estudios Cooperativos, Primer Cuatrimestre, No 107, pp 7-34. DOI: 10.5209/rev_REVE.2012.v107.38746.

Gutiérrez, M. y Palomo, R. (2012) Los sistemas institucionales de protección como respuesta de la banca cooperativa española ante la crisis: hacia la búsqueda de la eficiencia en su integración, CIRIEC-España, Revista de Economía Pública, Social y Cooperativa, $\mathrm{N}^{\mathrm{o}} 76$, pp. 27-50.

King, B. (2014) Breaking Banks: The innovators, Rogues, and strategists rebooting banking. Estados Unidos: John Wiley Sons Inc.

Massanell, J. A. (2016) La transformación de la banca: reorientación de los canales y servicios digitales. Papeles de Economía Española, No 149, pp. 93-99.

Maudos, J. (2017a) Modelos de negocio en la banca europea: cambios. Cuadernos de Información Económica, № 257, marzo, pp. 11-25.

Maudos, J. (2017b) El acceso a los servicios bancarios en España. El impacto de la reducción del número de oficinas. En: Maudos, J. El futuro del sector bancario español tras la reestructuración. Colección Mediterráneo Económico, № 29. Almería: Cajamar, pp. 265-286.

Mínguez, F. (2011) La estructura del nuevo marco prudencial y supervisor: hacia Basilea III. Mecanismos de prevención y gestión de futuras crisis bancarias. Fundación de Estudios Financieros, № 42, pp. 83-96. 
Morris, L. (2006) Business Model Innovation: The Strategy of Business Breakthroughs. International Journal of Innovation Science, Vol. 1, $\mathrm{N}^{\mathrm{o}} 4$, pp. 191-204. https://doi.org/10.1260/1757-2223.1.4.191.

Oliver Wyman (2014) Cooperative Banking: Leveraging the cooperative difference to adapt to a new environment. Oliver Wyman Financial Services.

Palomo, R. (2017) El cooperativismo de crédito frente a los restos del sector financiero: desafíos y oportunidades en un nuevo entorno socio-tecnológico. En Maudos, J. (Coord.): El futuro del sector bancario español tras la reestructuración. Mediterráneo Económico, N. 29, pp. 289-310.

Zachariadis, M.; Ozcan, P. (2017) The API Economy and Digital Transformation in Financial Services: The Case of Open Banking. SWIFT Institute Working Paper, N ${ }^{\mathrm{o}}$ 2016-001. http://dx.doi.org/10.2139/ssrn.2975199.

Zott, C.; Amit, R. (2007) Business model design and the performance of intrepreneurial firms. Organization Science, N ${ }^{\circ}$ 18, pp. 181-199.

https://doi.org/10.1287/orsc.1060.0232.

Anexo. 1. Ficha técnica de la muestra.

\begin{tabular}{|l|l|}
\hline Universo & Cooperativas de crédito españolas \\
\hline Tamaño de la población & 62 entidades \\
\hline Tamaño de la muestra & 41 entidades \\
\hline Metodología & Encuesta online anónima (plataforma Eval\&Go) \\
\hline Período de realización & $20 / 03 / 2018-25 / 04 / 2018$ \\
\hline Preguntas & 20 \\
\hline
\end{tabular}

Fuente: elaboración propia. 